Article

\title{
Optimal Operational Adjustment of a Community-Based Off-Grid Polygeneration Plant using a Fuzzy Mixed Integer Linear Programming Model
}

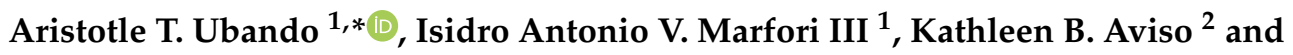 \\ Raymond R. Tan ${ }^{2}$ \\ 1 Mechanical Engineering Department, De La Salle University, 2401 Taft Avenue, Manila 0922, Philippines; \\ isidro.marfori@dlsu.edu.ph \\ 2 Chemical Engineering Department, De La Salle University, 2401 Taft Avenue, Manila 0922, Philippines; \\ kathleen.aviso@dlsu.edu.ph (K.B.A.); raymond.tan@dlsu.edu.ph (R.R.T.) \\ * Correspondence: aristotle.ubando@dlsu.edu.ph; Tel.: +632-524-4611
}

Received: 31 December 2018; Accepted: 7 February 2019; Published: 16 February 2019

\begin{abstract}
Community-based off-grid polygeneration plants based on micro-hydropower are a practical solution to provide clean energy and other essential utilities for rural areas with access to suitable rivers. Such plants can deliver co-products such as purified water and ice for refrigeration, which can improve standards of living in such remote locations. Although polygeneration gives advantages with respect to system efficiency, the interdependencies of the integrated process units may come as a potential disadvantage, due to susceptibility to cascading failures when one of the system components is partially or completely inoperable. In the case of a micro-hydropower-based polygeneration plant, a drought may reduce electricity output, which can, in turn, reduce the level of utilities available for use by the community. The study proposes a fuzzy mixed-integer linear programming model for the optimal operational adjustment of an off-grid micro-hydropower-based polygeneration plant seeking to maximize the satisfaction levels of the community utility demands, which are represented as fuzzy constraints. Three case studies are considered to demonstrate the developed model. The use of a diesel generator for back-up power is considered as an option to mitigate inoperability during extreme drought conditions.
\end{abstract}

Keywords: off-grid polygeneration; micro-hydropower plant; fuzzy optimization; mixed-integer linear programming; dual-turbine; multi-objective

\section{Introduction}

In developing countries, high priority is given to providing access to clean electricity and other essential utilities in remote communities [1]. Access to such amenities is critical to enhancing the quality of life and achieving the Sustainable Development Goals (SDGs) [2]. The seventh SDG focuses on universal access to affordable and reliable energy [3], but as recent as 2014, more than 1 billion people (i.e., about $15 \%$ of world population) still had no access to electricity [4]. The lack of access is especially true for geographically isolated rural communities, for which grid connectivity may not be economically or physically viable.

Efforts in providing power to off-grid communities have been pursued to address the rural electrification issue. From 2008 to 2017, the global off-grid renewable energy capacity has grown by about $300 \%$, providing about $6.5 \mathrm{GW}$ in total [5]. The integration of various renewable energy technologies to locally integrated energy sectors (LIES) have been found to significantly reduce 
the resource consumption and carbon footprint associated with energy supply [6]. Despite the dependence to climatic conditions and the inherent variability of renewable energy sources, a hybrid power system was proposed to combine renewable energy technologies with conventional energy sources while minimizing the cost and energy losses [7], and accommodating uncertainties, especially in remote areas [8]. The development of off-grid renewable energy systems largely varies and depend on the locally available resources and requirements of the community. In the past decade, an increase in the demand for solar energy solutions has been observed as solar photovoltaic (PV) technology matures [5]. However, for areas where access to flowing bodies of water is possible, micro-hydropower plants are a practical choice for irrigation and to generate electricity for the community [9]. Micro-hydropower plants are a robust and inexpensive renewable energy option [10]. In the context of hybrid power systems, micro-hydropower plants present a viable renewable energy option, given the right geographic location with good power generation potential [11]. A typical off-grid community will also require other utilities, such as purified water for household use. Aside from access to electricity and clean water, such communities may also require ice to preserve their produce (e.g., fish or vegetables). Polygeneration systems have been designed previously to provide such basic requirements [12]. These systems provide an efficient, integrated means to produce multiple material and energy products, which leads to improved system-wide efficiency and reduced emissions, waste, and natural resource consumption [13]. Polygeneration is generally defined as the co-production of various outputs along with electricity; the co-products can include heat (i.e., steam or hot water), cold energy (e.g., ice or chilled water), purified water, and chemical products [14]. In a polygeneration system, the interdependencies among integrated process units make the whole system vulnerable to cascading failures [10]. An operational disruption of such nature arising from any portion of the system leads to the causal operational disturbance cascading through the entire process network. Such disruption significantly affects the overall performance of the system causing divergence from the operational production state of the system [15]. Process systems engineering (PSE) models can play an important role to minimize production loss while maximizing opportunities to operate at an abnormal state for a brief period of time. The optimization approach may then be utilized to find the optimal operational adjustment of a polygeneration system at a perturbed state. A disruptive event, which can be caused by an external (e.g., natural disaster) or internal (e.g., equipment malfunction) trigger, can be measured via a dimensionless index known as inoperability [16]. The inoperability concept may be applied in representing operational disruption using the inoperability input-output modelling (IIM) framework [17]. In the context of a process network such as the polygeneration system, the inoperability can be defined as the loss of capacity of a system to operate relative to its normal state, and is represented by a dimensionless number ranging from a value of 0 (fully operational) to 1 (fully non-operational). This index has been used extensively in the literature. A linear programming (LP) model has been utilized for the optimal allocation of resources aiming to minimize losses in the event of a disruption [18]. The IIM theory was further developed in detail presenting case studies of disruption such as malevolent attacks [19]. The IIM framework has later been used as a sequential decision support tool for bioenergy systems [20]. It has been extended to deal with energy-related problems such as the optimization of the energy supply chain [21] and the identification of process bottlenecks in energy systems [22].

This work focuses on presenting a novel application of the inoperability concept on the operational adjustment of a community-based off-grid micro-hydropower-based polygeneration plant. Micro-hydropower plants generate up to $100 \mathrm{~kW}$ of electricity [23], which is enough for a small community with 20 to 30 households. Methods for the design [24], feasibility assessment [25], and identification of near-optimal solutions [26] for such facilities have been conducted previously. However, few studies have been conducted for micro-hydropower-based polygeneration systems for remote communities. An off-grid polygeneration system has been designed by Ray et al. [27] for an off-grid community in India using an LP model incorporating economic and reliability analysis. A generic decision support software was developed by Khalilpour and Vassallo [28] for the optimal 
design of a polygeneration system for off-grid distributed generation and storage system. However, neither of these studies incorporated micro-hydropower plants as a technology option. Recent studies on the optimal design of a micro-hydropower based polygeneration plant have been conducted using fuzzy optimization models. Such formulations are characterized by non-sharp boundaries of feasible regions, such that constraints can be partially satisfied as defined by their membership functions [29]. A fuzzy LP (FLP) model was developed by Ubando et al. [30] for the optimal design of an off-grid polygeneration plant using a superstructure that includes a micro-hydropower plant, a biomass-based Stirling engine, an ice plant, a diesel engine, and a sewage treatment facility. The work was later extended to a fuzzy mixed-integer linear programming (FMILP) model by Ubando et al. [12] considering vapor compression and absorption chillers as refrigeration options. However, these models were developed for system planning and design, and lack the capability to be used for optimal operational adjustment under abnormal conditions. An off-grid micro-hydropower-based polygeneration system is susceptible to drought which can reduce water flowrate available for the turbines; also, mechanical problems with system components may take longer to repair due to the time delays in bringing spare parts to the site. Kasivisvanathan et al. [15] developed a mixed-integer linear programming (MILP) model which provided the solution for the optimal operational adjustment of a gas-fired polygeneration plant for commercial use. In this study, the objective function is to maximize the operating profit (or minimize economic losses) of the system while employing the inoperability in each process in cases when the system experiences a disruption. A P-graph approach to the same problem was later developed by Tan et al. [31]. In the case of a polygeneration plant for a remote community, it is necessary to consider the demand for each product separately, depending on the needs of the inhabitants. This aspect is addressed in this work using fuzzy optimization using the approach developed by Zimmerman [29]. This approach is known as a "symmetric" fuzzy optimization model, where both constraints and (multiple) objectives are represented by fuzzy membership functions. FLP has been previously used for the optimal design of systems such as combined heat and power plants [32], trigeneration plants [33], and integrated biorefineries [34]. It was extended later to fuzzy MILP (FMILP) for the optimal planning of bioenergy parks [35], multifunctional bioenergy systems [36], and biofuel supply chain networks [37]. However, these models again focused on system design rather than abnormal operations.

This study develops an FMILP model for the optimal operational adjustment of a micro-hydropower-based polygeneration system for off-grid communities. It is assumed that the likely disruption is in the form of drought with varying intensity, which can be introduced into the model as an inoperability parameter. Three case studies are used to demonstrate the efficacy of the developed model under different drought scenarios. The case studies consider different turbine configurations and the option of having a diesel generator back-up. The rest of the paper is organized as follows. The formal problem statement is given, followed by the model formulation. Three case studies then follow. Lastly, conclusions and future prospects are discussed.

\section{Problem Statement}

The statement of the problem is formally defined similar to that proposed by Kasivisvanathan et al. [15] and stated as follows:

- An off-grid polygeneration system is assumed to have $M$ number of products and $N$ number of installed process units.

- The process units are characterized by fixed input-output stream proportions described by either the yield, efficiency, or the coefficient of performance, depending on the appropriate factor for each unit.

- Each process unit is defined by a minimum part-load operating level below which unstable or uneconomical operation occurs. The input-output ratios of streams for each unit remain fixed for the entire feasible operating range bound by a lower limit (minimum part-load operating level) and an upper limit (the rated capacity with a safety factor). The operational flexibility of the 
off-grid polygeneration system is defined by this operational range. The off-grid polygeneration system is further assumed to operate at a new steady state mode where the inoperability transpires.

- For each product stream, a fuzzy membership function is defined to describe the limits on net output, as dictated by basic requirements of the community inhabitants and are assumed to be constant. The fuzzy membership functions are assumed to be linear, and can thus be defined by specifying upper and lower limits. The upper limits signify normal requirements, while the lower limits signify the bare minimum requirements.

- The problem is to determine the optimal adjustment of operating capacities and allocation of streams for each process unit given an inoperability on the availability of water (drought scenario).

\section{Fuzzy Mixed Integer Linear Programming Model}

The basic MILP model for optimizing abnormal operations was developed in a previous work, and is given in the Appendix A [15]. The weakness of such a formulation is that it places extreme preference for product streams of higher economic value, often at the expense of the other lower-value products. While applicable to many commercial or industrial applications, in the case of remote rural communities, the actual value of basic needs might not be fully reflected in their prices. Instead, a given community may have a set of subsistence-level requirements for essential supplies, all of which need to be balanced based on what are deemed as tolerable shortages. These limits can in turn be modelled as fuzzy membership functions. Thus, the basic MILP model is modified into a fuzzy model to allow for such balanced rationing of capacity during a crisis [38]. The fuzzy MILP model is composed of the objective function and the constraints. The objective function of the model is shown in Equation (1):

$\operatorname{maximize} \lambda$

where $\lambda$ is the degree of satisfaction which is represented in every membership function in the model. The $\lambda$-value maximizes the lowest degree of satisfaction achieved among all identified fuzzy objectives. The degrees of satisfaction range from 0 to 1 , with 1 signifying complete satisfaction, 0 indicating undesirable result, and values between 0 to 1 illustrating partial satisfaction of the objective. In Figure 1 , the degree of satisfaction allows the translation of a variable-value shown in the abscissa into values ranging from 0 to 1 in the ordinate following a linear relation known as the linear membership function.

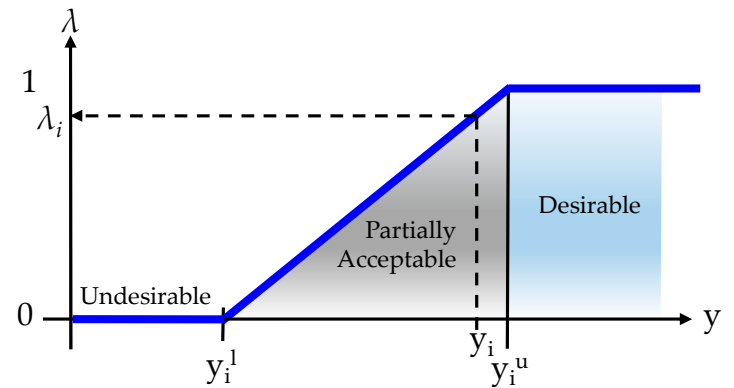

(a)

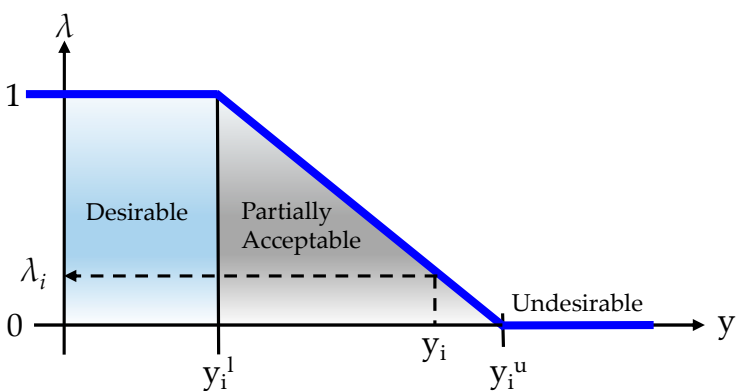

(b)

Figure 1. The fuzzy linear membership function for (a) maximization, and (b) minimization.

The optimal operational adjustment of the off-grid polygeneration system is subject to the following constraints. The technology matrix is introduced to define the optimal product output of the polygeneration system together with the process scaling vector as shown in Equation (2):

s.t.

$$
\mathbf{A} \mathbf{x}=\mathbf{y}
$$

where $\mathbf{A}$ is the technology matrix consisting of elements $\mathbf{a}_{i j}$ where $i$ represents the product stream and $j$ represents the technology considered. The technology matrix $\mathbf{A}$ is defined by a steady-state operational 
material and energy balance which are assumed to be scale invariant. In cases where the material or energy stream is identified as a raw material to a process, the value in matrix $\mathbf{A}$ would be represented by a negative value. Similarly, the positive values in matrix A represent the product or by-product streams generated from a process. The process scaling vector $\mathbf{x}$ with all elements equal to 1 , indicates that all processes $j$ in the system are operating in their optimal capacity. As the drought scenario sets in, the optimal operation adjustment in the off-grid polygeneration will be reflected in the change in values of $\mathbf{x}$. The product output $\mathbf{y}$ of the off-grid polygeneration system represents the optimal production level of each product stream $i$. The product demand limits utilize membership functions which maximize the product output levels of the polygeneration system given a threshold demand range described in Equation (3). The application of the linear membership function for maximization was introduced by Zimmermann [39] using a fuzzy set framework:

$$
\begin{array}{cc}
\mathbf{y}_{i} \geq \mathbf{y}_{i}{ }^{l}+\lambda\left(\mathbf{y}_{i}{ }^{u}-\mathbf{y}_{i}{ }^{l}\right) & \forall i \\
\mathbf{y}_{i} \leq \mathbf{y}_{i}{ }^{u}+\lambda\left(\mathbf{y}_{i}{ }^{l}-\mathbf{y}_{i}{ }^{u}\right) & \forall i=\text { fuel }
\end{array}
$$

where $\mathbf{y}_{i}{ }_{i}$ is the lower threshold limit of each material or energy stream $i$, and $\mathbf{y}_{i}{ }^{u}$ is the upper threshold limit of each material or energy stream $i$. Equation (3) represents the fuzzy linear membership function for maximizing a product stream. In Equation (3), any value less than $\mathbf{y}_{i}{ }^{l}$ is considered undesirable while any value greater than $\mathbf{y}_{i}{ }^{u}$ is highly desirable for a product stream $\mathrm{y}_{i}$. The values between $\mathbf{y}_{i}{ }^{l}$ and $\mathbf{y}_{i}{ }^{u}$ are considered as partially acceptable where degrees of satisfaction are described by a linear function with a slope of $\lambda$. Equation (4) represents the fuzzy linear membership function for minimizing a product stream which in this case is the fuel. For minimizing the fuel stream in Equation (4), $\mathbf{y}^{l}$ is the highly desired value, $\mathbf{y}^{u}$ is the undesirable value, and the values in between are treated as partially acceptable values. The diagram for the fuzzy linear membership function for maximization used in Equation (3) and for minimization used in Equation (4) are shown in Figure 1. The introduction of the drought scenario is described by Equation (5):

$$
\mathbf{y}_{i}>(1-D) \mathbf{y}_{i}^{*} \quad \forall i \in R
$$

where $D$ is the drought intensity factor with values ranging from $0 \%$ to $100 \%$. A drought intensity factor of $D=0$ represents a no drought scenario signifying full operational flow level of the river water during normal condition, while a drought intensity factor of $D=1 \mathrm{implies}$ that there is no river water flowing. The $\mathbf{y}_{i}{ }^{*}$ is the normal product output vector which represents the state of fully operational flow levels for all products $i$ in the subset of $R$. The subset of $R$ identifies all products which utilize the river water as raw material. The introduction of the binary variable vector is shown in Equations (6)-(8):

$$
\begin{array}{cc}
\mathbf{b}_{j} \mathbf{x}_{j}^{l} \leq \mathbf{x}_{j} \leq \mathbf{b}_{j} \mathbf{x}_{j}{ }^{u} & \forall j \\
\mathbf{b}_{j} \in\{0,1\} & \forall j \\
\mathbf{f}^{l} \leq \Sigma_{j} \mathbf{b}_{j} \leq \mathbf{f}^{u} & \forall j \in E
\end{array}
$$

The operational capacity limit of each technology $j$ is described by the lower limit operational capacity $\mathbf{x}_{j}{ }^{l}$ and the upper limit operational capacity $\mathbf{x}_{j}{ }^{u}$. Equation (7) defines whether a technology $j$ should operate $\left(\mathbf{b}_{j}=1\right)$ or not $\left(\mathbf{b}_{j}=0\right)$ during the chosen scenario. The topological binary constraint for the simultaneous selection of power generating technologies within a subset of $E$ is shown in Equation (8) where the subset $E$ represents all power generating technologies. The number of allowable operating technologies is limited by the minimum and maximum number defined by $\mathrm{f}^{l}$ and $\mathrm{f}^{u}$, respectively. The introduction of the binary variable vector $\mathbf{b}$ in Equations (6)-(8), enables the developed model in becoming a mixed-integer linear programming which provided the selection of 
the appropriate technology for the off-grid polygeneration system. Lastly, Equation (9) ensures that the $\lambda$-value falls within the range of 0 to 1 :

$$
0 \leq \lambda \leq 1
$$

It should be noted that equipment capital cost and stream prices are not included in the model. In the context of operational optimization, all equipment are assumed to have sunk costs, and there is no longer an option to modify them within any given scenario (Kasivisvanathan et al., [15]). Also, as the model deals with crisis conditions for remote rural communities, it is assumed that actual physical requirements for basic needs take precedence over cost considerations during the emergencies envisioned in this work. The model is solved utilizing Lingo 12.0, linked with MS Excel using the object linking and embedding (OLE) function of Lingo. The computer hardware used is powered by an Intel Core i7 processor with 8 GB of random access memory (RAM). Computational time for the examples in this work was negligible.

\section{Case Study}

Three case studies are presented to demonstrate the model developed. The first case study focuses on a basic off-grid community-based polygeneration system using a single turbine micro-hydropower plant. The second case study uses the same system in Case Study 1, but considers an additional back-up diesel generator. The third case study considers a dual turbine, instead of a single turbine, coupled with a back-up diesel generator.

\subsection{Case Study 1}

The case study considers a community of approximately 500 people requiring electricity, clean water, and ice. A single-turbine micro-hydropower plant produces $105 \mathrm{~kW}$ of electricity. Since this case study excludes the use of the diesel generator set as a back-up power generator, An ultra-filtration (UF) water treatment facility is considered to produce the required potable water for the community inhabitants, while a centralized ice plant provides for the cooling and refrigeration needs. The balanced process matrix of the case study is shown in Table 1. This matrix also shows the allocation of water flow to various uses within the community (including irrigation downstream of the micro-hydropower plant). The water flow allocation to the community shown in the table allows a dedicated water source for the production of clean water and ice. While a dedicated water flow allocation for the micro-hydropower plant is quantified in the table for power generation purposes. As per convention, positive and negative values in the process matrix signify outputs and inputs into any given process respectively.

Table 1. The balanced process matrix of case study 1 .

\begin{tabular}{cccccccc}
\hline Product Stream & Units & WTC $^{\mathbf{1}}$ & WTM $^{\mathbf{2}}$ & UFWT $^{\mathbf{3}}$ & Ice Plant & MHP $^{\mathbf{4}}$ & Product/Raw Materials \\
\hline Clean Water & $\mathrm{t} /$ day & 0 & 0 & 20 & -5 & 0 & 15 \\
Ice & $\mathrm{t} /$ day & 0 & 0 & 0 & 5 & 0 & 5 \\
Electricity & $\mathrm{kW}$ & 0 & 0 & -1 & -4 & 105 & 100 \\
Water to community supply & $\mathrm{t} /$ day & 50 & 0 & -50 & 0 & 0 & 0 \\
Water to microhydro plant & $\mathrm{t} /$ day & 0 & 52,500 & 0 & 0 & $-52,500$ & 0 \\
Rejected Water & $\mathrm{t} /$ day & 0 & 0 & 30 & 0 & 0 & 30 \\
River Water & $\mathrm{t} /$ day & -50 & $-52,500$ & 0 & 0 & 0 & $-52,550$ \\
Diesel & $\mathrm{t} /$ day & 0 & 0 & 0 & 0 & 0 & 0 \\
\hline
\end{tabular}

${ }^{1}$ Water to Community; ${ }^{2}$ Water to Microhydro; ${ }^{3}$ Ultra-Filtration Water Treatment; ${ }^{4}$ Microhydro Plant.

Under normal conditions, the community requires $100 \mathrm{~kW}$ of electricity, $15 \mathrm{t} /$ day of purified water, and $5 \mathrm{t} /$ day of ice. These values define the upper limits of the fuzzy membership functions of product requirements. To meet these demands, the polygeneration plant requires a river water flowrate of 52,550 $\mathrm{t} /$ day. Under crisis conditions, it is assumed that the community needs a bare 
minimum of $50 \mathrm{~kW}$ of electricity, $10 \mathrm{t} /$ day of purified water, and $2 \mathrm{t} /$ day of ice. These values define the lower limits of the fuzzy membership functions of the product demands. It is also assumed that the micro-hydropower plant has a minimum part-load operating level equivalent to $45 \%$ of its rated capacity. The drought index represents the fractional reduction of river water flowrate relative to normal conditions. The case study is then solved at increasing levels of drought, using increments of $10 \%$. The polygeneration system schematic diagram is shown in Figure 2.

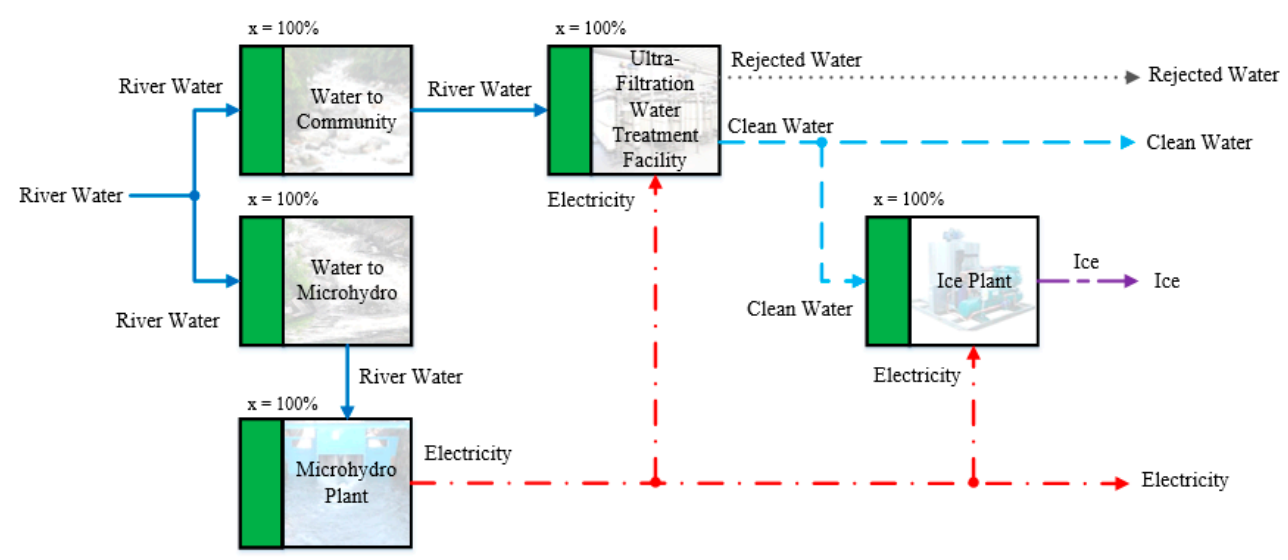

Figure 2. The process flowsheet of the polygeneration system of case study 1.

The optimal solutions to Case Study 1 for different drought intensities are shown in Table 2. The table shows the overall degree of satisfaction, $\lambda$, the optimal operating states of the process units, and the optimal net output levels of the products. As the drought level $D$ increases progressively to 0.50 (which represents $50 \%$ ), the value of $\lambda$, component operating states, and net output all decline. However, the increments of the $\lambda$-value are not evenly distributed due to the effect of the previously specified fuzzy membership functions of product requirements. For drought intensity levels of at least $D=0.60$ (or $60 \%$ ), it becomes impossible to find a feasible solution, which means that the bare minimum requirements of the community cannot be met. The optimal operating states of the polygeneration plant during a mild drought $(D=0.10)$ and moderate drought $(D=0.50)$ are shown in Figures 3 and 4 , respectively.

Table 2. The resulting process capacity factor and the optimal production level for case study 1.

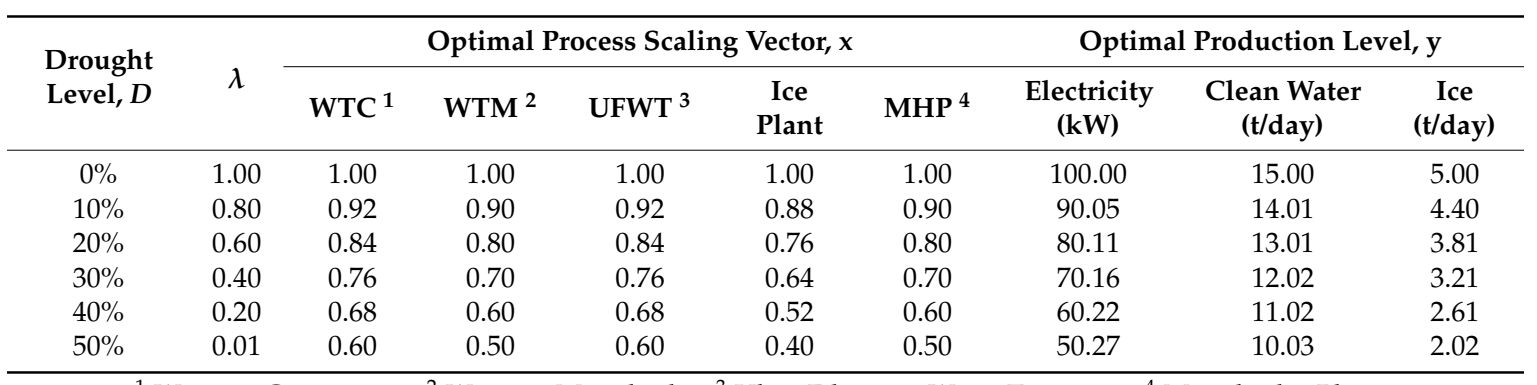

${ }^{1}$ Water to Community; ${ }^{2}$ Water to Microhydro; ${ }^{3}$ Ultra-Filtration Water Treatment; ${ }^{4}$ Microhydro Plant. 


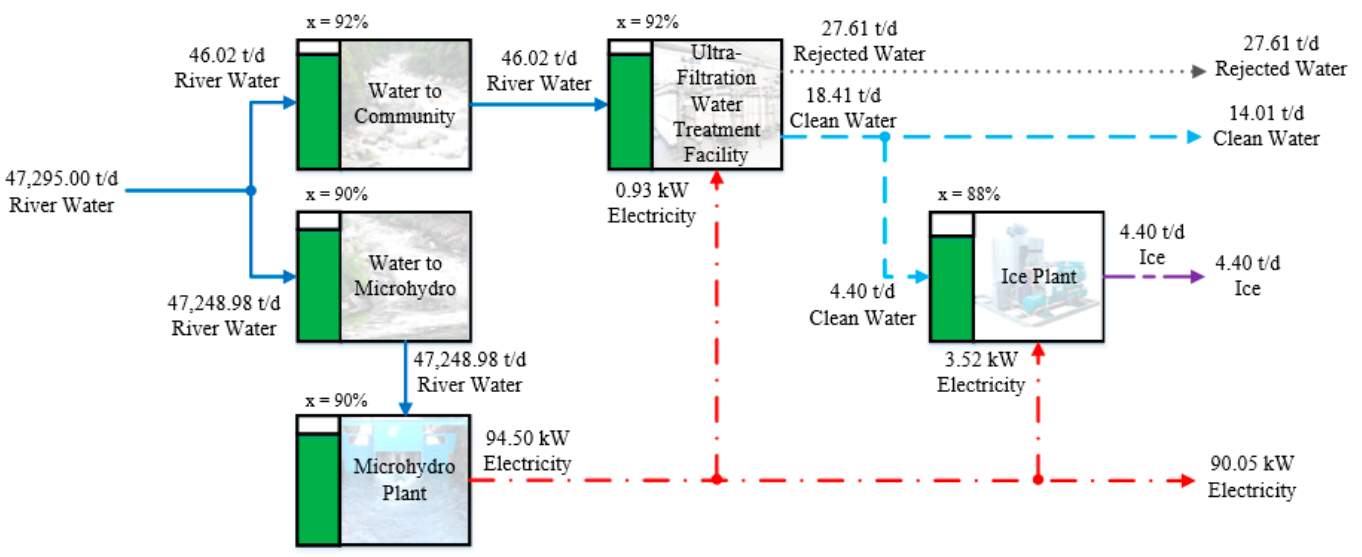

Figure 3. The optimal configuration of the polygeneration system of case study 1 under $D=0.10$ (or $10 \%$ ).

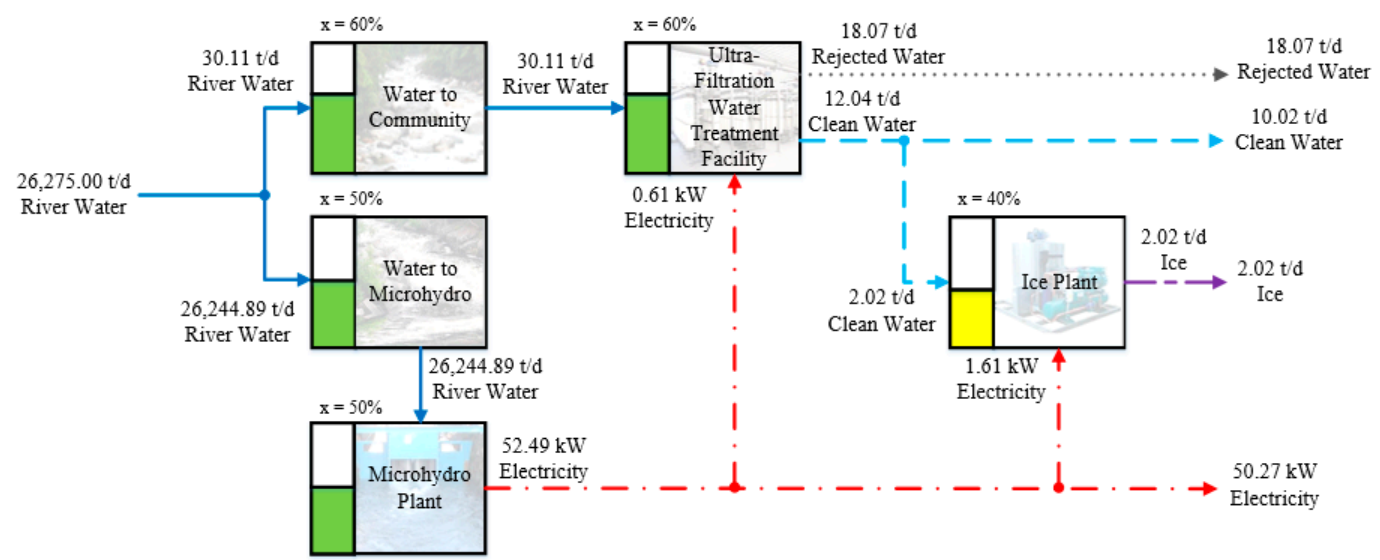

Figure 4. The optimal configuration of the polygeneration system of case study 1 under $D=0.50$ (or $50 \%$ ).

For $D=0.10$, it can be seen that the ice plant process unit had the lowest operability of $88 \%$ while the water treatment facility can still operate at $92 \%$ of its normal operating capacity. This scenario was aggravated when $D$ was up to 0.50 which resulted in the reduction in operating capacity of the ice plant to $40 \%$ and that of the water treatment facility to $60 \%$ of normal operating conditions. Furthermore, it can be noted that the ice plant is affected most since its disrupted state had an even higher disruption level (e.g., $12 \%$ and $60 \%$ disruption) than the experienced water reduction of $10 \%$ and $50 \%$.

\subsection{Case Study 2}

Case study 2, on the other hand, considers the effect of the additional back-up diesel generator to the system in the previous example. This diesel generator can produce supplementary electricity as the drought level intensifies. The capacity of the diesel generator comes in standard capacity size which in this case is a $60 \mathrm{~kW}$ capacity. The balanced process matrix of the polygeneration system incorporating the diesel generator is shown in Table 3. 
Table 3. The balanced process matrix of case study 2 .

\begin{tabular}{cccccccccc}
\hline Product Stream & Units & WTC $^{\mathbf{1}}$ & WTM $^{\mathbf{2}}$ & UFWT $^{3}$ & Ice Plant $^{\text {MHP }}$ & DGS $^{\mathbf{5}}$ & $\begin{array}{c}\text { Product/Raw } \\
\text { Materials }\end{array}$ \\
\hline Clean Water & t/day & 0 & 0 & 20 & -5 & 0 & 0 & 15 \\
Ice & t/day & 0 & 0 & 0 & 5 & 0 & 0 & 5 \\
Electricity & $\mathrm{kW}$ & 0 & 0 & -1 & -4 & 105 & 60 & 160 \\
Water to community supply & $\mathrm{t} /$ day & 50 & 0 & -50 & 0 & 0 & 0 & 0 \\
Water to microhydro plant & $\mathrm{t} /$ day & 0 & 52,500 & 0 & 0 & $-52,500$ & 0 & 0 \\
Rejected Water & $\mathrm{t} /$ day & 0 & 0 & 30 & 0 & 0 & 0 & 30 \\
River Water & $\mathrm{t} /$ day & -50 & $-52,500$ & 0 & 0 & 0 & 0 & $-52,550$ \\
Diesel & $\mathrm{t} /$ day & 0 & 0 & 0 & 0 & 0 & -3.6 & -3.6 \\
\hline
\end{tabular}

${ }^{1}$ Water to Community; ${ }^{2}$ Water to Microhydro; ${ }^{3}$ Ultra-Filtration Water Treatment; ${ }^{4}$ Microhydro Plant; ${ }^{5}$ Diesel Generator Set.

The remote community is assumed to have access to an emergency stock of diesel fuel. This supply, as well as the ease of delivery of additional fuel, is the basis for the fuzzy membership function of the diesel fuel input (in the input-output framework used here, inputs can be treated simply as products with negative net flowrates). In the case study, the diesel generator can operate from $30 \%$ to $100 \%$ of its rated capacity. With the addition of the diesel back-up generator, a binary variable is added to the model to indicate whether the diesel generator is switched on or off as the drought level intensifies (see Equations (6)-(8)). This feature leads to an FMILP formulation. The system schematic diagram is shown in Figure 5.

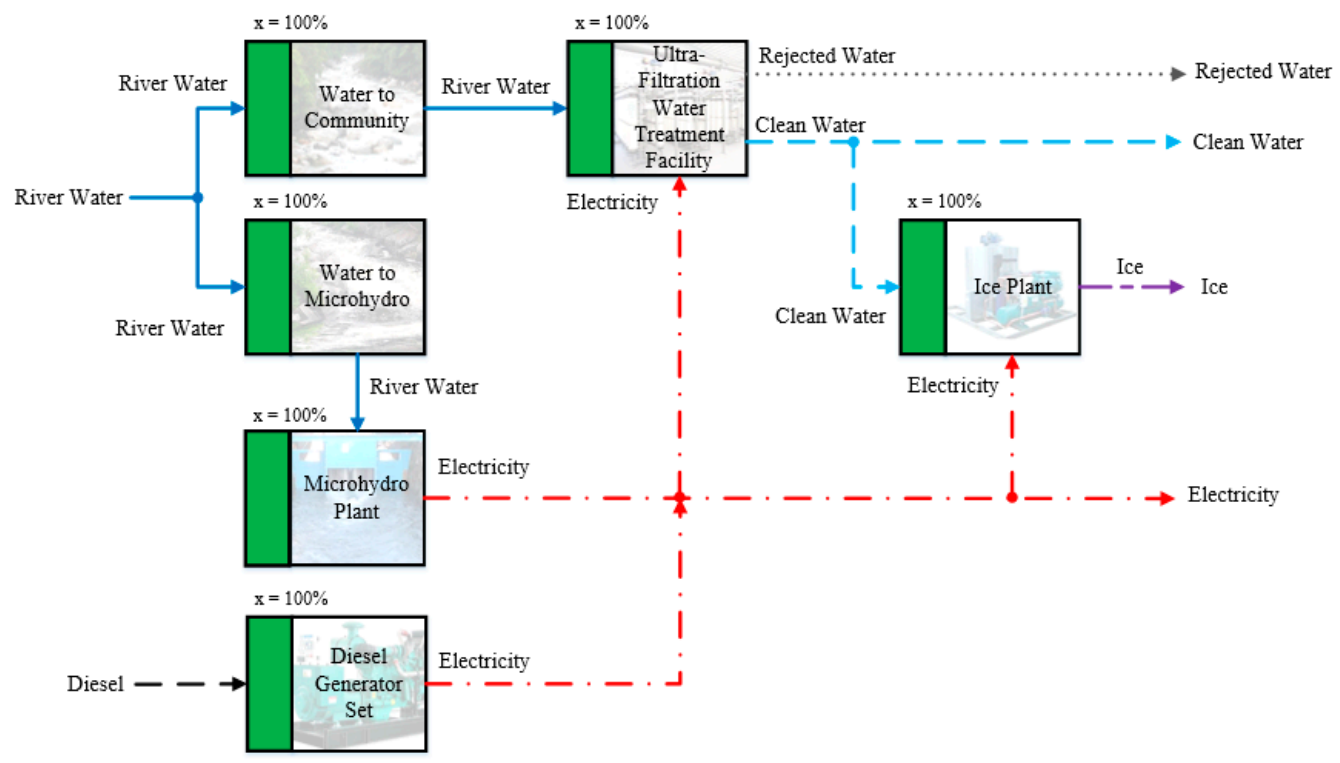

Figure 5. The process flowsheet of the polygeneration system of case study 2 .

The optimal results of case study 2 at different levels of drought intensity are shown in Table 4 . Note that the micro-hydropower plant ceases to operate at a drought level of $D=0.60$ and beyond. The back-up diesel generator begins to operate at a drought level of $D=0.20$ (or 20\%) and progressively increases output under dryer conditions. The back-up generator is able to protect the community from the impacts of severe drought by extending the operational functionality of the polygeneration system even after the micro-hydropower plant becomes fully inoperable. This switch occurs at a drought level of $D=0.60$ (or $60 \%$ ), the electricity of the community is solely produced from the back-up diesel generator set at $90 \%$ capacity. This suggests that even at extreme drought conditions where the micro-hydropower plant fails to operate, a smaller capacity diesel generator set of about $54 \mathrm{~kW}$ may be considered if it is available in the market. The optimal operating states of the polygeneration plant at $D=0.40$ and $D=0.90$ are shown in Figures 6 and 7, respectively. 
Table 4. The balanced process matrix of case study 2 .

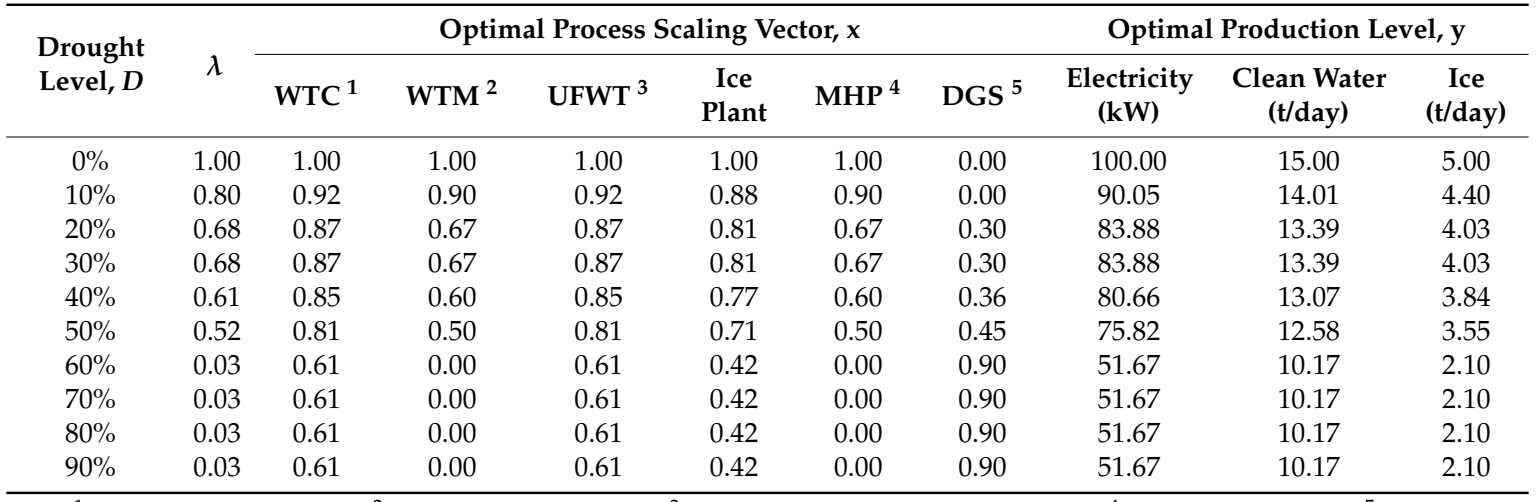

${ }^{1}$ Water to Community; ${ }^{2}$ Water to Microhydro; ${ }^{3}$ Ultra-Filtration Water Treatment; ${ }^{4}$ Microhydro Plant; ${ }^{5}$ Diesel Generator Set.

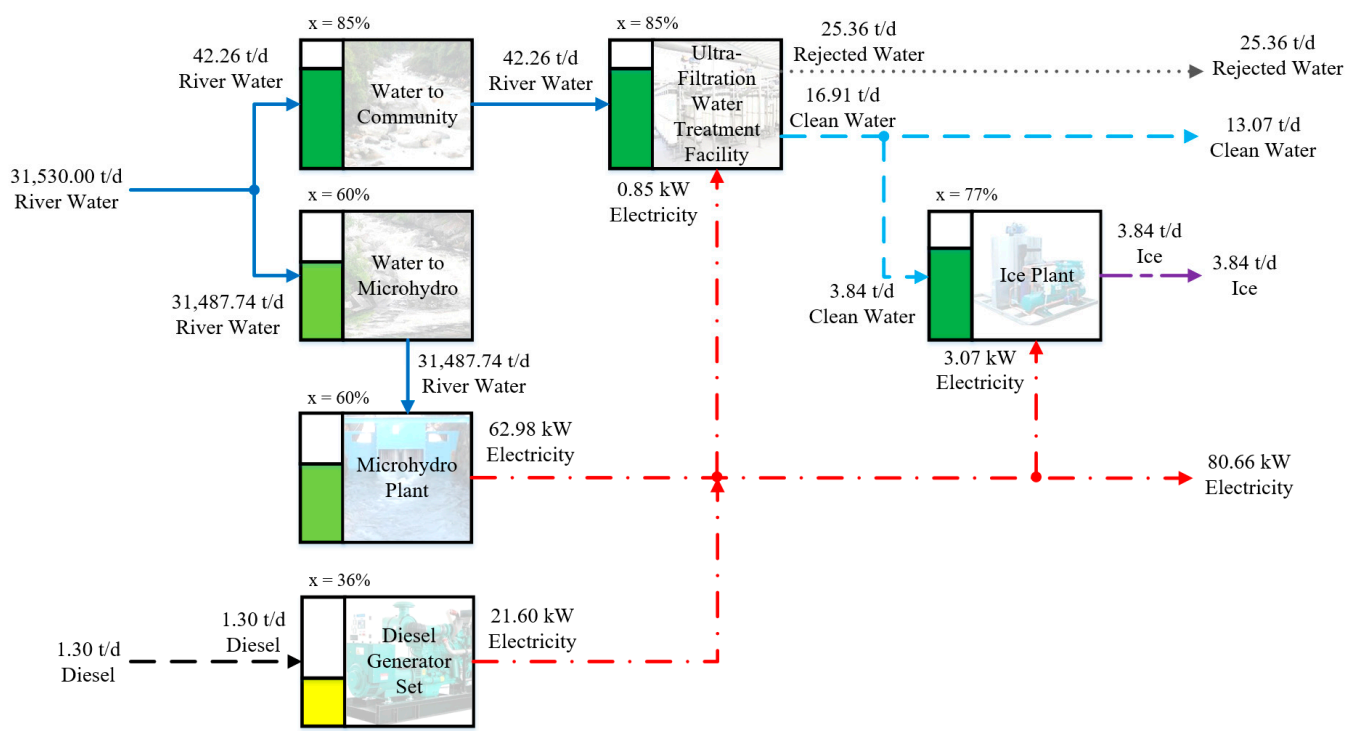

Figure 6. The optimal configuration of the polygeneration system of case study 2 under $D=0.40$ (or $40 \%$ ).

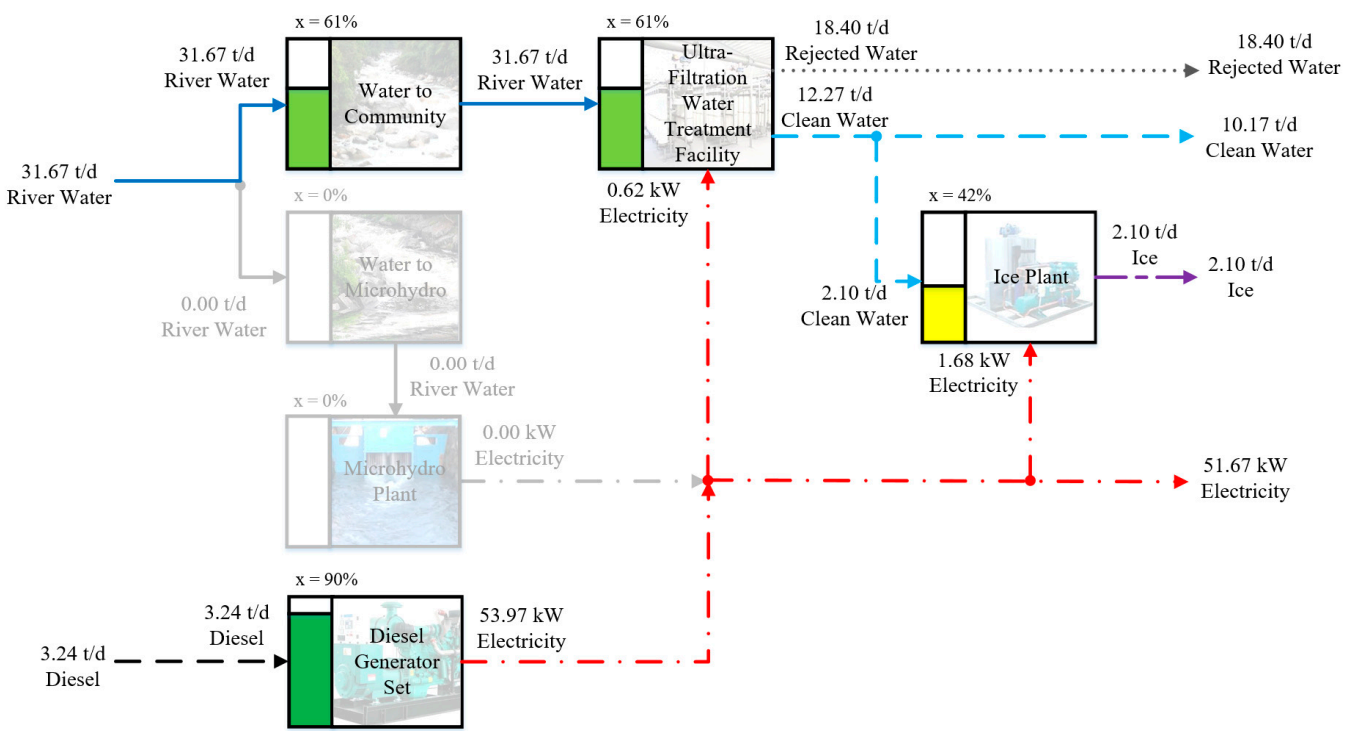

Figure 7. The optimal configuration of the polygeneration system of case study 2 under $D=0.90$ (or $90 \%$ ). 


\subsection{Case Study 3}

This case study is similar to the previous one, except that a dual-turbine micro-hydropower plant is assumed. This dual-turbine micro-hydro plant consists of two smaller turbines rated at $70 \mathrm{~kW}$ and $35 \mathrm{~kW}$, which together gives the system greater operational flexibility. The balanced process matrix for Case Study 3 is shown in Table 5 where the micro-hydropower turbines 1 and 2 are explicitly identified. With the reduction in the size of the turbine, this translates to a system-wide lower part-load operating capacity of $15 \mathrm{~kW}$ if only the $35 \mathrm{~kW}$ turbine is activated at $45 \%$ its rated capacity. The minimum part-load operating level for the $70 \mathrm{~kW}$ turbine and the $35 \mathrm{~kW}$ turbine of the micro-hydropower plant is defined as $45 \%$ [40]. Each turbine is operated individually allowing for a more flexible means to electricity generation during drought scenarios. Similar to case study 2 , the back-up diesel generator set will be used as a support for the dual-turbine micro-hydropower plant if the need arises. The process flowsheet of case study 3 is shown in Figure 8.

Table 5. The balanced process matrix of case study 3 .

\begin{tabular}{|c|c|c|c|c|c|c|c|c|c|}
\hline Product Stream & Units & WTC $^{1}$ & $\mathrm{WTM}^{2}$ & UFWT $^{3}$ & Ice Plant & MHT1 $^{4}$ & MHT2 $^{5}$ & DGS $^{6}$ & $\begin{array}{c}\text { Product/Raw } \\
\text { Materials }\end{array}$ \\
\hline Clean Water & t/day & 0 & 0 & 20 & -5 & 0 & 0 & 0 & 15 \\
\hline Ice & $t /$ day & 0 & 0 & 0 & 5 & 0 & 0 & 0 & 5 \\
\hline Electricity & $\mathrm{kW}$ & 0 & 0 & -1 & -4 & 70 & 35 & 60 & 160 \\
\hline Water to community supply & $\mathrm{t} /$ day & 50 & 0 & -50 & 0 & 0 & 0 & 0 & 0 \\
\hline Water to microhydro plant & $t /$ day & 0 & 52,500 & 0 & 0 & $-35,000$ & $-17,500$ & 0 & 0 \\
\hline Rejected Water & $\mathrm{t} /$ day & 0 & 0 & 30 & 0 & 0 & 0 & 0 & 30 \\
\hline River Water & $\mathrm{t} /$ day & -50 & $-52,500$ & 0 & 0 & 0 & 0 & 0 & $-52,550$ \\
\hline Diesel & $t /$ day & 0 & 0 & 0 & 0 & 0 & 0 & -3.6 & -3.6 \\
\hline
\end{tabular}

${ }^{1}$ Water to Community; ${ }^{2}$ Water to Microhydro; ${ }^{3}$ Ultra-Filtration Water Treatment; ${ }^{4}$ Microhydro Turbine $1 ;{ }^{5}$ Microhydro Turbine $2 ; 6$ Diesel Generator Set.

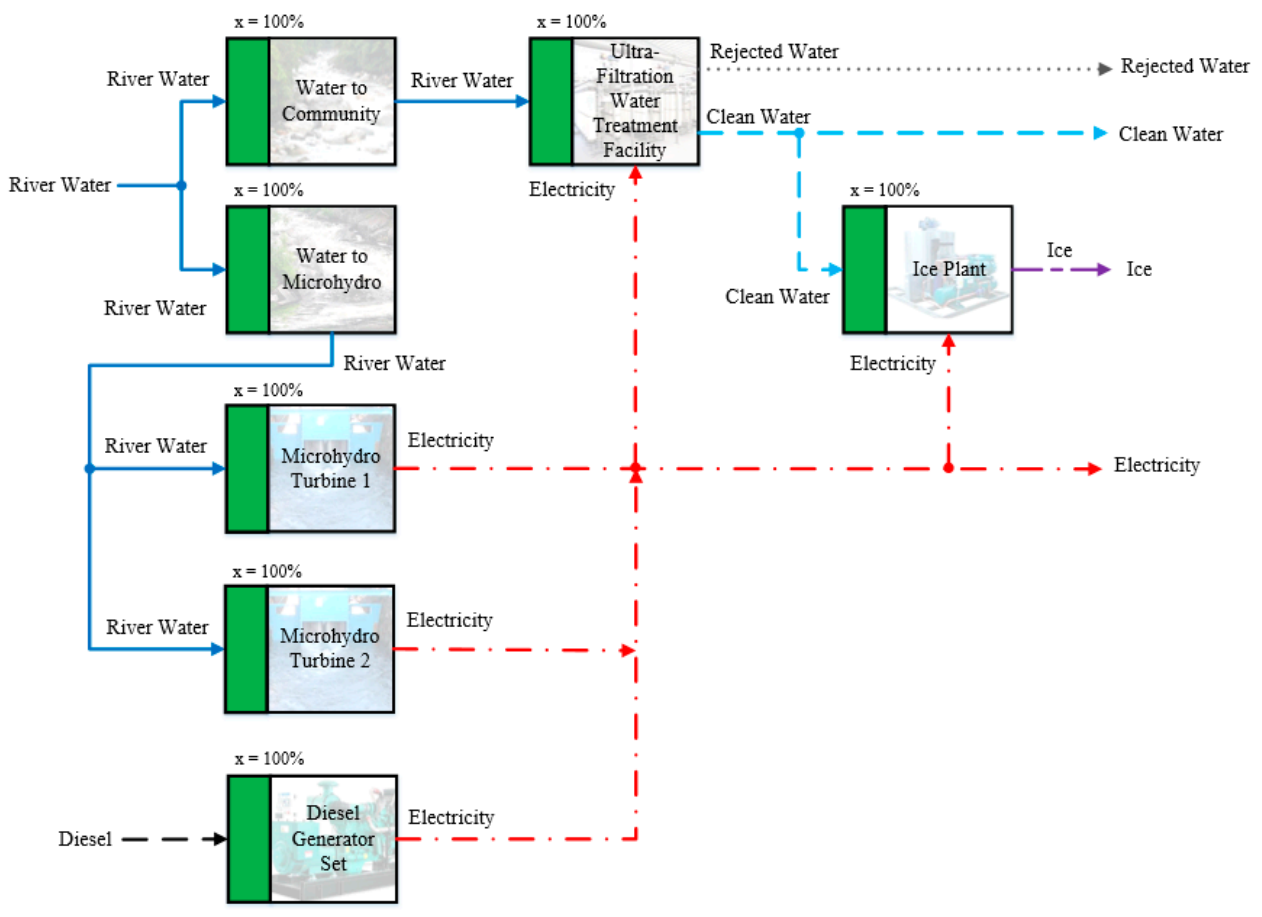

Figure 8. The process flowsheet of the polygeneration system of case study 3.

The optimal operational adjustment results for case study 3 using various levels of $D$ is shown in Table 6. The table shows the dynamic operational capacity of the 2 micro-hydro turbines through varying drought intensity levels. It can be observed that turbine 2 will shut off at drought intensity levels of $D=0.40$ and 0.50 and will operate again at $D=0.70$ and 0.80 . 
Table 6. The resulting process capacity factor and the optimal production level for case study 3.

\begin{tabular}{|c|c|c|c|c|c|c|c|c|c|c|c|}
\hline \multirow{2}{*}{$\begin{array}{l}\text { Drought } \\
\text { Level, } D\end{array}$} & \multirow[b]{2}{*}{$\lambda$} & \multicolumn{7}{|c|}{ Optimal Process Scaling Vector, $x$} & \multicolumn{3}{|c|}{ Optimal Production Level, y } \\
\hline & & WTC $^{1}$ & WTM $^{2}$ & UFWT $^{3}$ & $\begin{array}{l}\text { Ice } \\
\text { Plant }\end{array}$ & MHT1 $^{4}$ & MHT2 $^{5}$ & DGS $^{6}$ & $\begin{array}{c}\text { Electricity } \\
(\mathbf{k W})\end{array}$ & $\begin{array}{c}\text { Clean Water } \\
\text { (t/day) }\end{array}$ & $\begin{array}{c}\text { Ice } \\
\text { (t/day) }\end{array}$ \\
\hline $10 \%$ & 0.80 & 0.92 & 0.90 & 0.92 & 0.88 & 1.00 & 0.70 & 0.00 & 90.05 & 14.01 & 4.40 \\
\hline $20 \%$ & 0.68 & 0.87 & 0.80 & 0.87 & 0.81 & 0.70 & 1.00 & 0.30 & 97.90 & 13.39 & 4.03 \\
\hline $30 \%$ & 0.68 & 0.87 & 0.70 & 0.87 & 0.81 & 0.55 & 1.00 & 0.30 & 87.39 & 13.39 & 4.03 \\
\hline $60 \%$ & 0.36 & 0.77 & 0.40 & 0.77 & 0.65 & 0.60 & 0.00 & 0.54 & 70.99 & 12.10 & 3.26 \\
\hline $70 \%$ & 0.32 & 0.73 & 0.30 & 0.73 & 0.59 & 0.00 & 0.90 & 0.63 & 66.15 & 11.62 & 2.97 \\
\hline $80 \%$ & 0.23 & 0.69 & 0.20 & 0.69 & 0.54 & 0.00 & 0.60 & 0.72 & 61.32 & 11.13 & 2.68 \\
\hline $90 \%$ & 0.13 & 0.61 & 0.00 & 0.61 & 0.42 & 0.00 & 0.00 & 0.90 & 51.67 & 10.17 & 2.10 \\
\hline
\end{tabular}

${ }^{1}$ Water to Community; ${ }^{2}$ Water to Microhydro; ${ }^{3}$ Ultra-Filtration Water Treatment; ${ }^{4}$ Microhydro Turbine $1 ;{ }^{5}$ Microhydro Turbine 2; ${ }^{6}$ Diesel Generator Set.

Turbine 1, on the other hand, will continue to operate until it reaches a drought intensity of $D=0.60$ and will shut off at $D=0.70$ and beyond. At elevated drought intensity of $D=0.70$ and 0.80 , the smaller turbine provides better operational flexibility allowing appropriate operational adjustments. As a supplementary source of power, the back-up diesel generator begins to operate at a drought intensity of $D=0.20$ and is partially operated until a drought intensity level of $D=0.90$ at $90 \%$ part-load capacity. However, the dual-turbine remains operable over a wider range of conditions allowing operational flexibility on drought condition while the diesel generator partially operates from $D=0.20$ to 0.90 . The optimal configuration of the polygeneration system for case study 3 is shown in Figures 9 and 10 for $D=0.30$ and $D=0.90$, respectively.

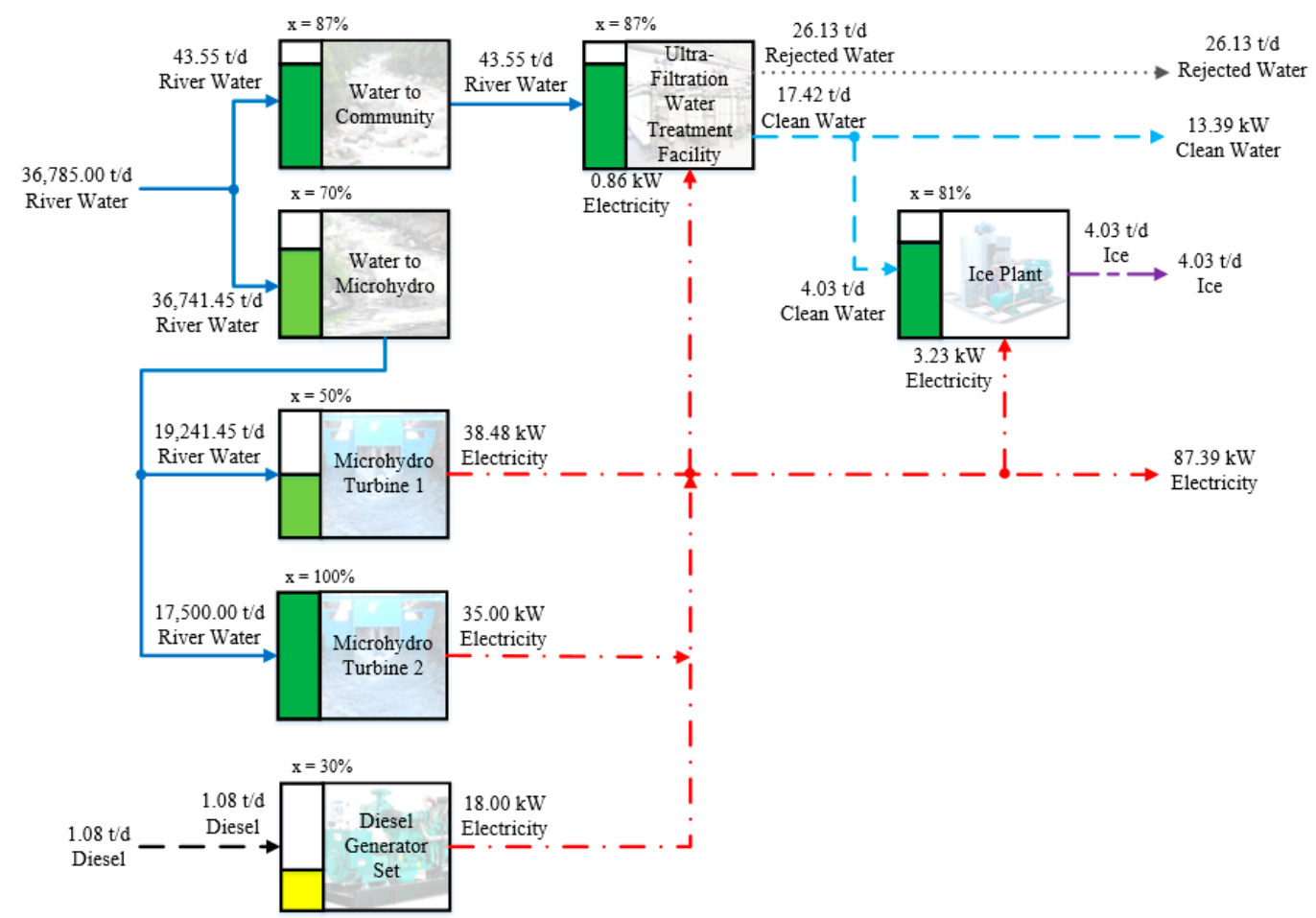

Figure 9. The optimal configuration of the polygeneration system of case study 3 under $D=0.30$ (or $30 \%$ ). 


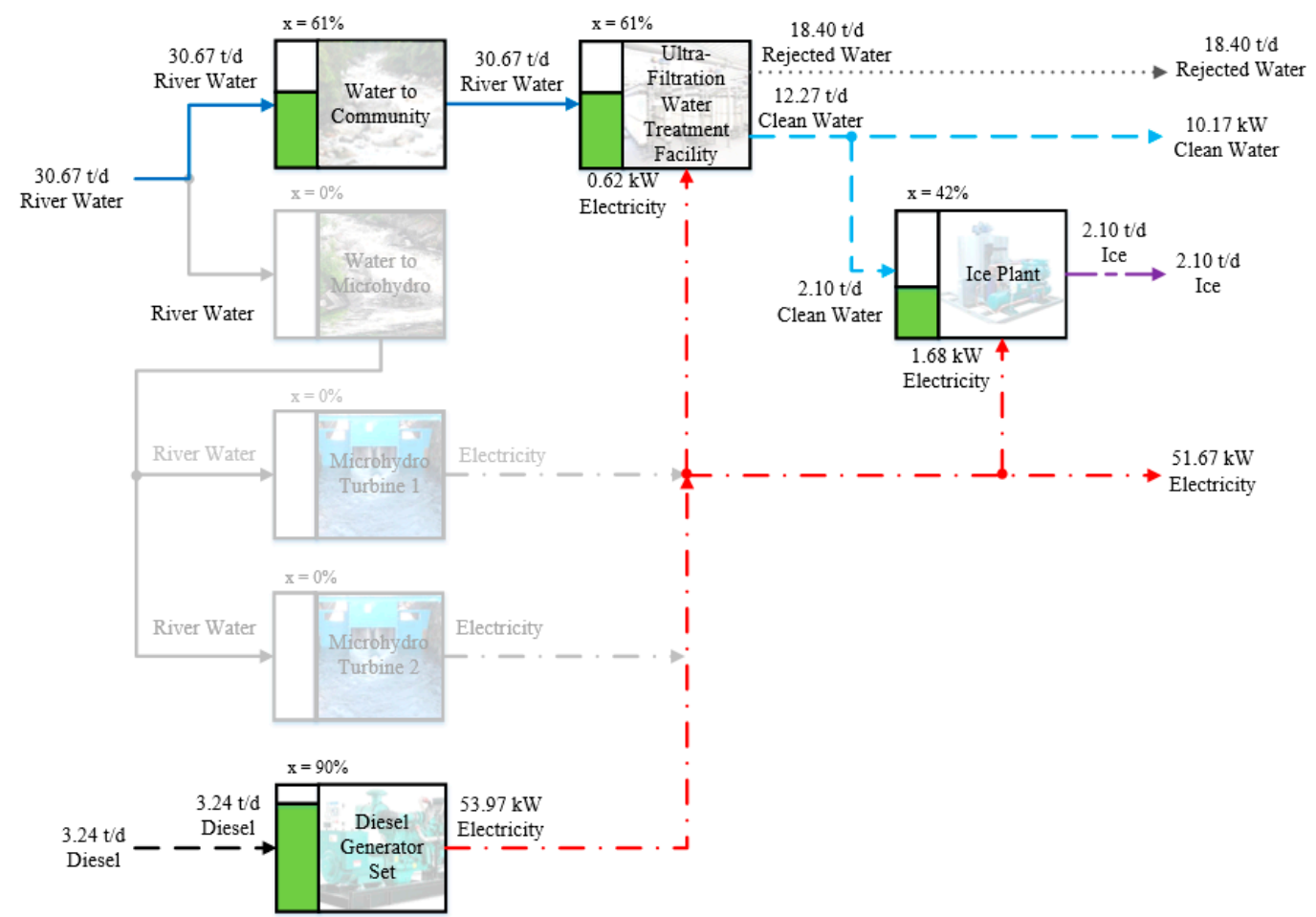

Figure 10. The optimal configuration of the polygeneration system of case study 3 under $D=0.90$ (or $90 \%$ ).

The comparison of the production level of electricity, water, and ice for the three case studies are shown in Figure 11a-c while the diesel fuel consumption for case studies 2 and 3 is shown in Figure 11d. The contribution of the power generating technologies to electricity production for each case study are shown in Figure 12. The back-up diesel generator set enabled an extended production of electricity, water, and ice for the community especially during low to severe drought intensity levels. The dual-turbine micro-hydro assembly with diesel generator set (Case Study 3) provides a more stable production of electricity, water, and ice and is found to be superior compared to the single-turbine micro-hydro plant with diesel generator (Case Study 2) especially for drought intensity levels from $D=0.60$ to $D=0.80$. With lower diesel fuel consumption and higher electricity generation, the dual-turbine micro-hydro plant with diesel generator is ideal for areas where drought risk is expected.
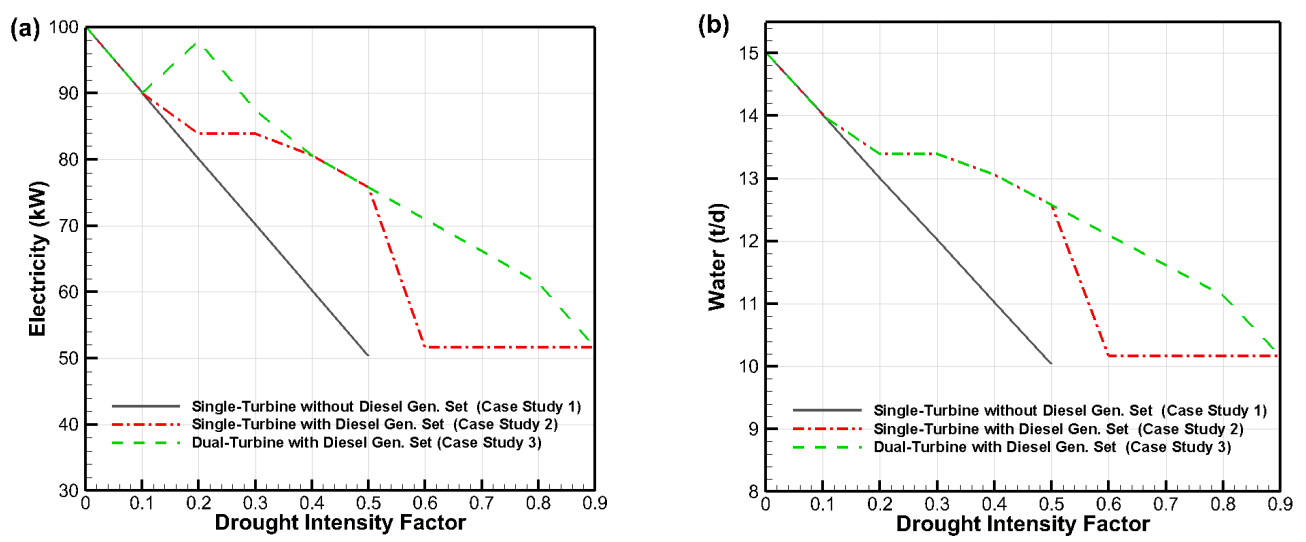

Figure 11. Cont. 
(c)

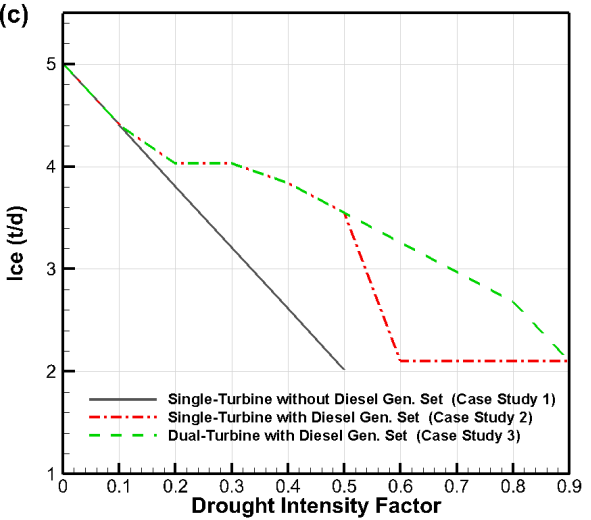

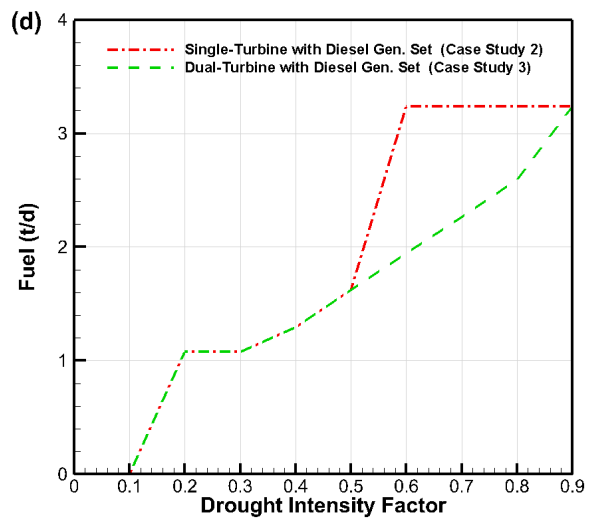

Figure 11. The optimal polygeneration product output of the polygeneration such as the (a) electricity, (b) water, and (c) ice, and the raw material such as the (d) diesel fuel.
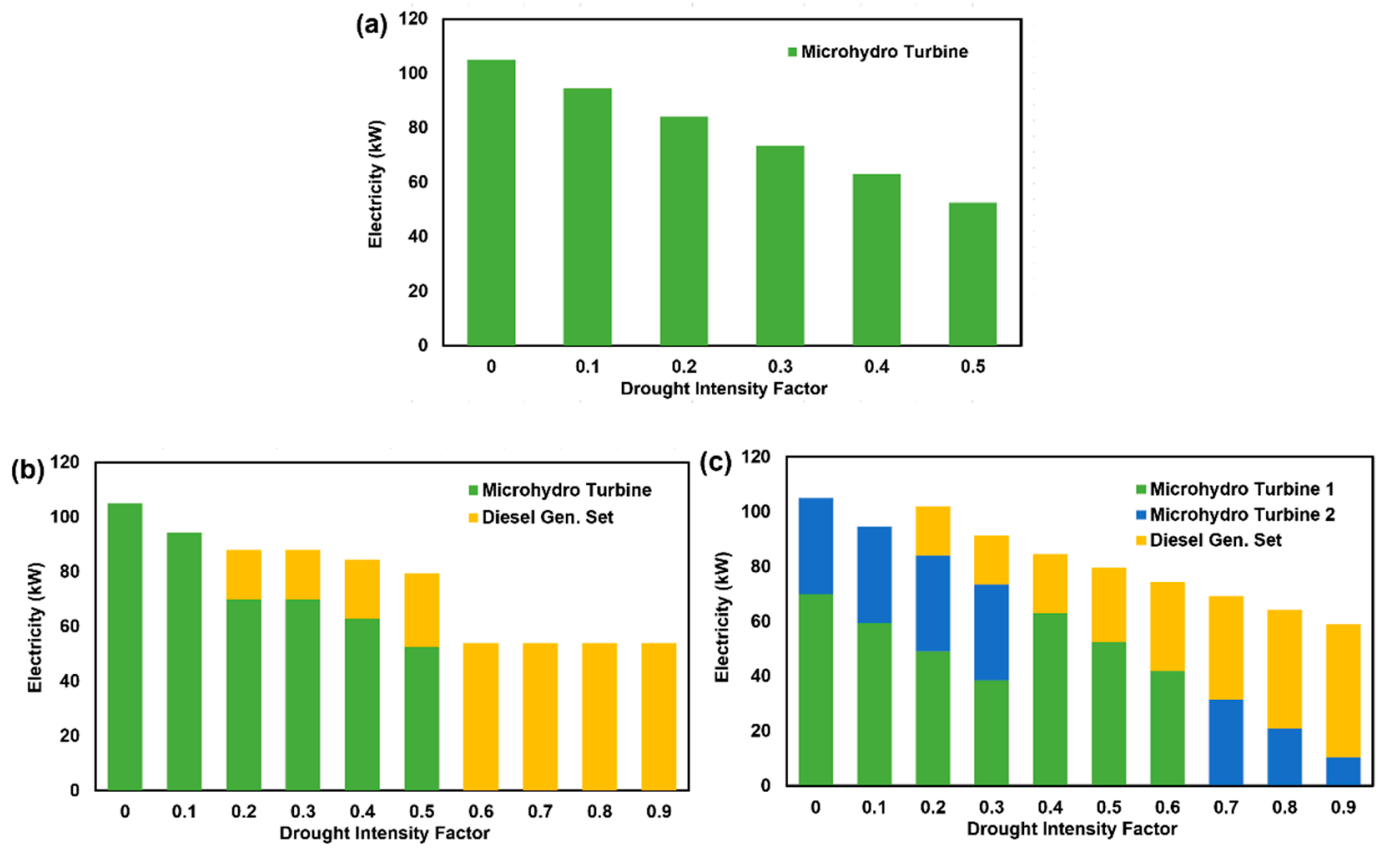

Figure 12. The resulting electricity generation contribution for (a) case study 1 , (b) case study 2, (c) case study 3.

\section{Conclusions}

A fuzzy MILP model has been developed for the optimal operational adjustment of an off-grid micro-hydropower-based polygeneration system under varying drought intensity scenarios. The polygeneration system produces electricity, purified water, and ice, which are the basic needs of an off-grid community. The model accounts for the integration of the process units to give the optimal operational adjustments needed to partially satisfy the community demands for each product output, based on fuzzy constraints. Unlike conventional MILP formulations, the fuzzy bounds provide an optimal solution that gives a more balanced compromise on the reduction of outputs of the facility. A variant of the model also considers the minimization of the fuel consumption of the back-up diesel generator set. Case studies that consider different turbine configurations and diesel back-up options were solved to illustrate the model capabilities. This modelling framework is useful for off-grid electricity systems which have been established and have failed to take into consideration system disruptions resulting from the effects of climate change. The model provides decision-makers with a systematic procedure for identifying the optimal operational adjustment to ensure that the community 
product demands are satisfied during abnormal conditions. Furthermore, the model can provide insights on the management of external sources of energy.

Future work can apply this model formulation to a broader range of integrated polygeneration systems and consider multi-period models to accommodate variations in product demands. In addition, the potential for the use of alternative methods such as fuzzy P-graph [41] to deal with problems of this class should also be explored together with an examination of the availability and performance of alternative operating conditions.

Author Contributions: All authors contributed to the completion and publication of the study. R.R.T. conceptualized the general idea of the paper. I.A.V.M.III provided key technical information on off-grid microhydro plants. R.R.T., K.B.A., and A.T.U., contributed on the development of the model. K.B.A. thoroughly verified and validated the model. A.T.U. prepared and edited the manuscript, and responsible for drawing the figures. I.A.V.M.III, K.B.A., and R.R.T. revised and reviewed the manuscript.

Funding: This research was funded by Philippine Commission on Higher Education (CHED) PHERNet Project.

Acknowledgments: The research is supported by the Philippine Commission on Higher Education (CHED) PHERNet Sustainability Studies Program and the De La Salle Science Foundation (DLS-SFI) for the publication cost. The pioneering work of the late Godofredo Salazar is acknowledged in establishing the Center for Microhydro Research at De La Salle University.

Conflicts of Interest: The authors declare no conflict of interest.

\section{Appendix A}

The basic MILP model for optimizing the polygeneration system during abnormal operations is described by Equations (A1)-(A7) and is similar to the model introduced in [14].

$$
\begin{gathered}
\max =\mathbf{c}^{\mathrm{T}} \mathbf{y}^{*} \\
\mathbf{A} \cdot \mathbf{x}=\mathbf{y}^{*} \\
\mathbf{b}^{\mathrm{T}} \mathbf{x}^{l} \leq \mathbf{x} \leq \mathbf{b}^{\mathrm{T}} \mathbf{x}^{u} \\
\mathbf{b} \in\{0,1\} \\
\mathrm{y}^{*} \text { river_water }=(1-\mathrm{D}) \text { Yriver_water } \\
\mathbf{y}^{*} \geq \mathbf{y}^{l} \\
\mathbf{f}^{l} \leq \mathbf{b}^{\mathrm{T}} \mathbf{e} \leq \mathrm{f}^{u}
\end{gathered}
$$

The objective function (Equation (A1)) is to maximize the profit of the system, excluding capital cost recovery, where $c^{T}$ represents the price vector for the material or energy streams and $\mathbf{y}^{*}$ is the net output vector during abnormal operations. The model is subject to material and energy balances (Equation (A2)) dependent on the process operational conditions where $\mathbf{A}$ is the balanced process matrix during normal operating conditions and $\mathbf{x}$ is the process scaling vector during abnormal conditions. The scaling vector is bound by the lower $\left(\mathbf{x}^{l}\right)$ and upper $\left(\mathbf{x}^{u}\right)$ operating capacity limits of each available technology (Equation (A3)) where $\mathbf{b}^{\mathrm{T}}$ is a binary variable (Equation (A4)) indicating whether a technology is operational $\left(\mathbf{b}_{i}=1\right)$ or not $\left(\mathbf{b}_{i}=0\right)$ during abnormal operations. The abnormal conditions occur when there is insufficient river water (Equation (A5)) defined by the drought intensity factor, D. Furthermore, a minimum production level $\left(\mathbf{y}^{l}\right)$ for identified product streams must be met (Equation (A6)). There is also a minimum $\left(\mathrm{f}^{l}\right)$ and maximum $\left(\mathrm{f}^{u}\right)$ number of operational technologies at any given time (Equation (A7)), vector e represents a column vector with all elements equal to 1.

\section{References}

1. The World Bank. Designing Sustainable off-Grid Rural Electrification Projects: Principles and Practices; Research Working Papers; The World Bank: Washington, DC, USA, 2008. 
2. $\quad$ Banerjee, S.G.; Bhatia, M.; Portale, E.; Schers, J.; Dorner, D.; Azuela, G.E.; Jaques, I.S.; Ashok, P.E.; Bushueva, I.; Angelou, N.; et al. Global Tracking Framework. Sustain. Energy All World Bank 2013, 3, 289.

3. United Nations. Affordable and Clean Energy: Energy Efficient; United Nations: New York, NY, USA, 2018.

4. The World Bank. State of Energy Access Report 2017; The World Bank: Washington, DC, USA, 2017.

5. IRENA. Off-Grid Renewable Energy Solutions: Global and Regional Status and Trends; IRENA: Abu Dhabi, UAE, 2018; pp. 1-20.

6. Perry, S.; Klemeš, J.; Bulatov, I. Integrating waste and renewable energy to reduce the carbon footprint of locally integrated energy sectors. Energy 2008, 33, 1489-1497. [CrossRef]

7. Lee, J.Y.; Aviso, K.B.; Tan, R.R. Optimal Sizing and Design of Hybrid Power Systems. ACS Sustain. Chem. Eng. 2018, 6, 2482-2490. [CrossRef]

8. Lee, J.Y.; Lu, Y.C.; Aviso, K.B.; Tan, R.R. Mathematical programming for optimal design of hybrid power systems with uncertainties. Chem. Eng. Trans. 2018, 70, 67-72.

9. Geem, Z.W. Optimal Scheduling of Multiple Dam System Using Harmony Search Algorithm. In Computational and Ambient Intelligence; IWANN 2007. Lecture Notes in Computer Science; Sandoval, F., Prieto, A., Cabestany, J., Graña, M., Eds.; Springer: Berlin/Heidelberg, Germany, 2007; Volume 4507, pp. 316-323.

10. Agarkar, B.D.; Barve, S.B. A Review on Hybrid solar/wind/hydro power generation system. Int. J. Curr. Eng. Technol. 2011, 4, 188-191.

11. Walmsley, T.G.; Walmsley, M.R.W.; Varbanov, P.S.; Klemeš, J.J. Energy Ratio analysis and accounting for renewable and non-renewable electricity generation: A review. Renew. Sustain. Energy Rev. 2018, 98, 328-345. [CrossRef]

12. Ubando, A.T.; Marfori, I.A.V.; Aviso, K.B.; Tan, R.R. Optimal synthesis of a community-based off-grid polygeneration plant using fuzzy mixed integer linear programming model. Chem. Eng. Trans. 2018, 70, 955-960.

13. Serra, L.M.; Lozano, M.-A.; Ramos, J.; Ensinas, A.V.; Nebra, S.A. Polygeneration and efficient use of natural resources. Energy 2009, 34, 575-586. [CrossRef]

14. Adams, T.A.; Ghouse, J.H. Polygeneration of fuels and chemicals. Curr. Opin. Chem. Eng. 2015, 10, 87-93. [CrossRef]

15. Kasivisvanathan, H.; Barilea, I.D.U.; Ng, D.K.S.; Tan, R.R. Optimal operational adjustment in multi-functional energy systems in response to process inoperability. Appl. Energy 2013, 102, 492-500. [CrossRef]

16. Haimes, Y.Y.; Jiang, P. Leontief-based model of risk in complex interconnected infrastructures. J. Infrastruct. Syst. 2001, 7, 1-12. [CrossRef]

17. Leontief, W. The Structure of American Economy, 1919-1929: An Empirical Application of Equilibrium Analysis; Harvard University Press: Cambridge, MA, USA, 1941; p. 181.

18. Jiang, P.; Haimes, Y.Y. Risk management for Leontief-based interdependent systems. Risk Anal. 2004, 24, 1215-1229. [CrossRef] [PubMed]

19. Haimes, Y.Y.; Horowitz, B.M.; Lambert, J.H.; Santos, J.R.; Crowther, K.; Lian, C. Inoperability input-output model for interdependent infrastructure sectors. I: Theory and methodology. J. Infrastruct. Syst. 2005, 11, 80-92. [CrossRef]

20. Santos, J.R.; Barker, K.; Zelinke, P.J. Sequential decision-making in interdependent sectors with multiobjective inoperability decision trees: Application to biofuel subsidy analysis. Econ. Syst. Res. 2008, 20, $29-56$. [CrossRef]

21. Tan, R.R. A general source-sink model with inoperability constraints for robust energy sector planning. Appl. Energy 2011, 88, 3759-3764. [CrossRef]

22. Tan, R.R.; Lam, H.L.; Kasivisvanathan, H.; Ng, D.K.S.; Foo, D.C.Y.; Kamal, M.; Hallaler, N.; Klemeš, J.J. An algebraic approach to identifying bottlenecks in linear process models of multifunctional energy systems. Theoret. Found. Chem. Eng. 2012, 46, 642-650. [CrossRef]

23. Hoq, T.; Nawshad, U.A.; Islam, N.; Syfullah, K.; Rahman, R. Micro Hydro Power: Promising Solution for Off-grid Renewable Energy Source. Int. J. Sci. Eng. Res. 2011, 2, 2-6.

24. Pasalli, Y.R.; Rehiara, A.B. Design Planning of Micro-hydro Power Plant in Hink River. Procedia Environ. Sci. 2014, 20, 55-63. [CrossRef] 
25. Hongpeechar, B.; Krueasuk, W.; Poungching-Ngam, A.; Bhasaputra, P.; Pattaraprakorn, W. Feasibility study of micro hydro power plant for rural electrification in Thailand by using axial flux permanent magnet. In Proceedings of the 2011 International Conference and Utility Exhibition on Power and Energy Systems: Issues and Prospects for Asia, Pattaya City, Thailand, 28-30 September 2011; pp. 3-6.

26. Voll, P.; Jennings, M.; Hennen, M.; Shah, N.; Bardow, A. The optimum is not enough: A near-optimal solution paradigm for energy systems synthesis. Energy 2015, 82, 446-456. [CrossRef]

27. Ray, A.; Jana, K.; De, S. Polygeneration for an off-grid Indian village: Optimization by economic and reliability analysis. Appl. Therm. Eng. 2017, 116, 182-196. [CrossRef]

28. Khalilpour, K.R.; Vassallo, A. A generic framework for distributed multi-generation and multi-storage energy systems. Energy 2016, 114, 798-813. [CrossRef]

29. Zimmermann, H.J. Fuzzy programming and linear programming with several objective functions. Fuzzy Sets Syst. 1978, 1, 45-55. [CrossRef]

30. Ubando, A.T.; Marfori, I.A.; Culaba, A.B.; Dungca, J.R.; Promentilla, M.A.B.; Aviso, K.B.; Tan, R.R. A Systematic Approach for the Optimal Design of an Off-Grid Polygeneration System using Fuzzy Linear Programming Model. In Computer Aided Chemical Engineering; Espuña, A., Graells, M., Puigjaner, L., Eds.; Elsevier: Amsterdam, The Netherlands, 2017; Volume 40, pp. 2191-2196.

31. Tan, R.R.; Cayamanda, C.D.; Aviso, K.B. P-graph approach to optimal operational adjustment in polygeneration plants under conditions of process inoperability. Appl. Energy 2014, 135, 402-406. [CrossRef]

32. Chiu, G.M.K.; Aviso, K.B.; Ubando, A.T.; Tan, R.R. Fuzzy linear programming model for the optimal design of a combined cooling, heating, and power plant. In Proceedings of the 2017 IEEE 9th International Conference on Humanoid, Nanotechnology, Information Technology, Communication and Control, Environment and Management (HNICEM), Manila, Philippines, 1-3 December 2017; pp. 1-6.

33. Mayol, A.P.; Culaba, A.B.; Aviso, K.B.; Ng, D.K.S.; Tan, R.R.; Ubando, A.T. Fuzzy linear programming model for the optimal design of a trigeneration plant with product price variability. In Proceedings of the IEEE Region 10 Annual International Conference, Proceedings/TENCON, Singapore, 22-25 November 2017; pp. 3200-3205.

34. Ubando, A.T.; Culaba, A.B.; Tan, R.R.; Ng, D.K.S. A Systematic Approach for Optimization of an Algal Biorefinery Using Fuzzy Linear Programming. In Computer Aided Chemical Engineering; Karimi, I.A., Srinivasan, R., Eds.; Elsevier: Amsterdam, The Netherlands, 2012; Volume 31, pp. 805-809.

35. Ubando, A.T.; Culaba, A.B.; Aviso, K.B.; Tan, R.R.; Cuello, J.L.; Ng, D.K.S.; El-Halwagi, M.M. Fuzzy mixed integer non-linear programming model for the design of an algae-based eco-industrial park with prospective selection of support tenants under product price variability. J. Clean. Prod. 2016, 136, 183-196. [CrossRef]

36. Ubando, A.T.; Culaba, A.B.; Aviso, K.B.; Ng, D.K.S.; Tan, R.R. Fuzzy mixed-integer linear programming model for optimizing a multi-functional bioenergy system with biochar production for negative carbon emissions. Clean Technol. Environ. Policy 2014, 16, 1537-1549. [CrossRef]

37. Bairamzadeh, S.; Saidi-Mehrabad, M.; Pishvaee, M.S. Modelling different types of uncertainty in biofuel supply network design and planning: A robust optimization approach. Renew. Energy 2018, 116, 500-517. [CrossRef]

38. Tan, R.R.; Aviso, K.B.; Cayamanda, C.D.; Chiu, A.S.F.; Promentilla, M.A.B.; Ubando, A.T.; Yu, K.D.S. A fuzzy linear programming enterprise input-output model for optimal crisis operations in industrial complexes. Int. J. Prod. Econ. 2016, 181, 410-418. [CrossRef]

39. Zimmermann, H.-J. Fuzzy Set Theory- and Its Applications; Springer Seience+Business Media: New York, NY, USA, 1992.

40. Elbatran, A.H.; Yaakob, O.B.; Ahmed, Y.M.; Shabara, H.M. Operation, performance and economic analysis of low head micro-hydropower turbines for rural and remote areas: A review. Renew. Sustain. Energy Rev. 2015, 43, 40-50. [CrossRef]

41. Aviso, K.B.; Tan, R.R. Fuzzy P-graph for optimal synthesis of cogeneration and trigeneration systems. Energy 2018, 154, 258-268. [CrossRef]

(C) 2019 by the authors. Licensee MDPI, Basel, Switzerland. This article is an open access article distributed under the terms and conditions of the Creative Commons Attribution (CC BY) license (http:/ / creativecommons.org/licenses/by/4.0/). 